Article

\title{
Comparison of Hyperspectral Imaging and Near-Infrared Spectroscopy to Determine Nitrogen and Carbon Concentrations in Wheat
}

\author{
Iman Tahmasbian ${ }^{1, *(\mathbb{D})}$, Natalie K. Morgan ${ }^{2}$, Shahla Hosseini Bai ${ }^{3}$, Mark W. Dunlop ${ }^{1}$ (D) and Amy F. Moss ${ }^{2} \mathbb{D}$ \\ 1 Department of Agriculture and Fisheries, Queensland Government, Toowoomba, QLD 4350, Australia; \\ Scopus affiliation ID: 60028929; mark.dunlop@daf.qld.gov.au \\ 2 School of Environmental and Rural Science, University of New England, Armidale, NSW 2351, Australia; \\ nmorga20@une.edu.au (N.K.M.); amoss22@une.edu.au (A.F.M.) \\ 3 Centre for Planetary Health and Food Security, School of Environment and Science, Griffith University, \\ Brisbane, QLD 4111, Australia; s.hosseini-bai@griffith.edu.au \\ * Correspondence: iman.tahmasbian@daf.qld.gov.au
}

check for updates

Citation: Tahmasbian, I.; Morgan, N.K; Hosseini Bai, S.; Dunlop, M.W; Moss, A.F Comparison of

Hyperspectral Imaging and Near-Infrared Spectroscopy to Determine Nitrogen and Carbon Concentrations in Wheat. Remote Sens. 2021, 13, 1128. https://doi.org/ $10.3390 /$ rs13061128

Academic Editor: Yuxin Miao

Received: 15 January 2021

Accepted: 12 March 2021

Published: 16 March 2021

Publisher's Note: MDPI stays neutral with regard to jurisdictional claims in published maps and institutional affiliations.

Copyright: (C) 2021 by the authors Licensee MDPI, Basel, Switzerland. This article is an open access article distributed under the terms and conditions of the Creative Commons Attribution (CC BY) license (https:/ / creativecommons.org/licenses/by/ $4.0 /)$.

\begin{abstract}
Hyperspectral imaging (HSI) is an emerging rapid and non-destructive technology that has promising application within feed mills and processing plants in poultry and other intensive animal industries. HSI may be advantageous over near infrared spectroscopy (NIRS) as it scans entire samples, which enables compositional gradients and sample heterogenicity to be visualised and analysed. This study was a preliminary investigation to compare the performance of HSI with that of NIRS for quality measurements of ground samples of Australian wheat and to identify the most important spectral regions for predicting carbon $(\mathrm{C})$ and nitrogen $(\mathrm{N})$ concentrations. In total, 69 samples were scanned using an NIRS (400-2500 nm), and two HSI cameras operated in 400-1000 nm (VNIR) and 1000-2500 nm (SWIR) spectral regions. Partial least square regression (PLSR) models were used to correlate $\mathrm{C}$ and $\mathrm{N}$ concentrations of 63 calibration samples with their spectral reflectance, with 6 additional samples used for testing the models. The accuracy of the HSI predictions (full spectra) were similar or slightly higher than those of NIRS (NIRS $\mathrm{R}_{\mathrm{c}}^{2}$ for $\mathrm{C}=0.90$ and $\mathrm{N}=0.96$ vs. HSI $\mathrm{R}_{\mathrm{C}}^{2}$ for $\mathrm{C}(\mathrm{VNIR})=0.97$ and $\left.\mathrm{N}(\mathrm{SWIR})=0.97\right)$. The most important spectral region for $C$ prediction identified using HSI reflectance was 400-550 nm with $\mathrm{R}^{2}$ of 0.93 and RMSE of $0.17 \%$ in the calibration set and $\mathrm{R}^{2}$ of 0.86 , RMSE of $0.21 \%$ and ratio of performance to deviation (RPD) of 2.03 in the test set. The most important spectral regions for predicting $\mathrm{N}$ concentrations in the feed samples included 1451-1600 nm, 1901-2050 nm and 2051-2200 nm, providing prediction with $\mathrm{R}^{2}$ ranging from 0.91 to 0.93 , RMSE ranging from $0.06 \%$ to $0.07 \%$ in the calibration sets, $\mathrm{R}^{2}$ from 0.96 to 0.99 , RMSE of $0.06 \%$ and RPD from 3.47 to 3.92 in the test sets. The prediction accuracy of HSI and NIRS were comparable possibly due to the larger statistical population (larger number of pixels) that HSI provided, despite the fact that HSI had smaller spectral range compared with that of NIRS. In addition, HSI enabled visualising the variability of $\mathrm{C}$ and $\mathrm{N}$ in the samples. Therefore, HSI is advantageous compared to NIRS as it is a multifunctional tool that poses many potential applications in data collection and quality assurance within feed mills and poultry processing plants. The ability to more accurately measure and visualise the properties of feed ingredients has potential economic benefits and therefore additional investigation and development of HSI in this application is warranted.
\end{abstract}

Keywords: feed ingredients; hyperspectral imaging; machine learning; NIR spectroscopy; nondestructive; quality monitoring; real-time; wheat

\section{Introduction}

Feed accounts for more than $65 \%$ of live poultry production costs [1] and large safety margins are required to buffer variability in feed ingredient specifications when formulating diets [2]. Additionally, the integrated Australian chicken meat industry pellets over 
3 million tonnes of feed per annum [3]. Feed ingredients delivered to the feed mill are unable to be analysed via wet chemistry due to the large amount being processed on a daily basis. Consequently, near infrared spectroscopy (NIRS) calibrations are often used within integrated operations to instantaneously estimate the nutrient composition of feedstuffs. NIRS obtains only one reading of the sample per scan [4] and relies on the assumption that the sample is equally ground and homogenised, but in practice this may not be the case. This is problematic as the nutrient specifications of feed ingredients are highly variable, which is of concern as feed represents the major cost in the rearing of meat chickens (broilers). Thus, the chicken meat industry still faces the challenge of how to account for this variation in feed formulation [5]. For example, a database of over 2 million measurements (book values consisting of 102 nutrients from 42 different ingredients aggregated from 12 companies) were compared in Moss, et al. [6]. It was calculated that only $13 \%$ of the Australian data compiled meets the sample number required to accurately predict the mean value within $90 \%$ accuracy. Therefore, alternative methods are sought to address this issue, being able to scan the entire ingredients and measuring the nutritional values rapidly, accurately and inexpensively.

Hyperspectral imaging (HSI) is an emerging technology that has been stated to be one of the most promising techniques currently investigated for quality evaluation purposes [7-10]. HSI integrates spectroscopic and imaging techniques into one system, providing spectral and spatial information simultaneously [11-13]. This combined approach enables HSI to identify multiple components within a product and quantify the spatial distribution of these components so that the compositional gradient of a product can be calculated. HSI technology may be a better alternative to NIRS as it scans an entire sample taking readings from thousands to millions of pixels (depending on the sample size and spatial resolution of the camera) within an image, deriving average nutrient values and/or a compositional gradient from these readings [4]. The ability to analyse the spatial distribution of nutrients within the scanned samples and separate/visualise samples with differing properties may also enable the detection and analysis of multiple objects and identification of impurities [12] that are not uniformly distributed (and may not be present in subsamples). This makes HSI a powerful quality assurance tool with potential application within feed mills and poultry processing plants $[14,15]$. While HSI cameras can be costly, they are only essential for the initial calibration. Once the most important spectral ranges are identified, the HSI camera may be replaced with relatively affordable hand-held or fixed multispectral cameras that are tuned to target the previously identified spectra and suitable for industry use.

The aim of this study was a preliminary investigation to compare the performance of HSI with that of NIRS for quality measurements of ground samples of Australian wheat, identifying the variations within the samples and to identify the most important spectral regions for predicting $\mathrm{C}$ and $\mathrm{N}$ concentrations. We hypothesised that the larger statistical sample population achieved from the spatial dimension of hyperspectral images, compared to a single point measured by NIRS, would compensate for the limited spectral range of the HSI. We also hypothesised that the spatial dimension of HSI would enable identifying and visualising the variabilities in $\mathrm{C}$ and $\mathrm{N}$ concentrations in the samples.

\section{Materials and Methods}

\subsection{Experimental Design Overview}

In this study, we used ground wheat samples to compare $\mathrm{C}$ and $\mathrm{N}$ prediction accuracies obtained using an NIRS system and two HSI systems that together measured the same spectral range as the NIRS, 400-2500 nm (Figure 1). The comparison was conducted by using the same calibration and test samples and following the same procedure for both methods with an attempt to achieve the best prediction accuracy for each method. Common statistical tests were used for comparing the accuracies of the $\mathrm{C}$ and $\mathrm{N}$ concentrations predicted using the NIRS and HSI systems. We also compared the NIRS and HSI systems in terms of their ability for identifying and measuring the variations within the samples. 
In addition, we divided the spectra to subregions to find the most important spectral subregions for $\mathrm{C}$ and $\mathrm{N}$ predictions that can be possibly conducted using affordable multispectral cameras.

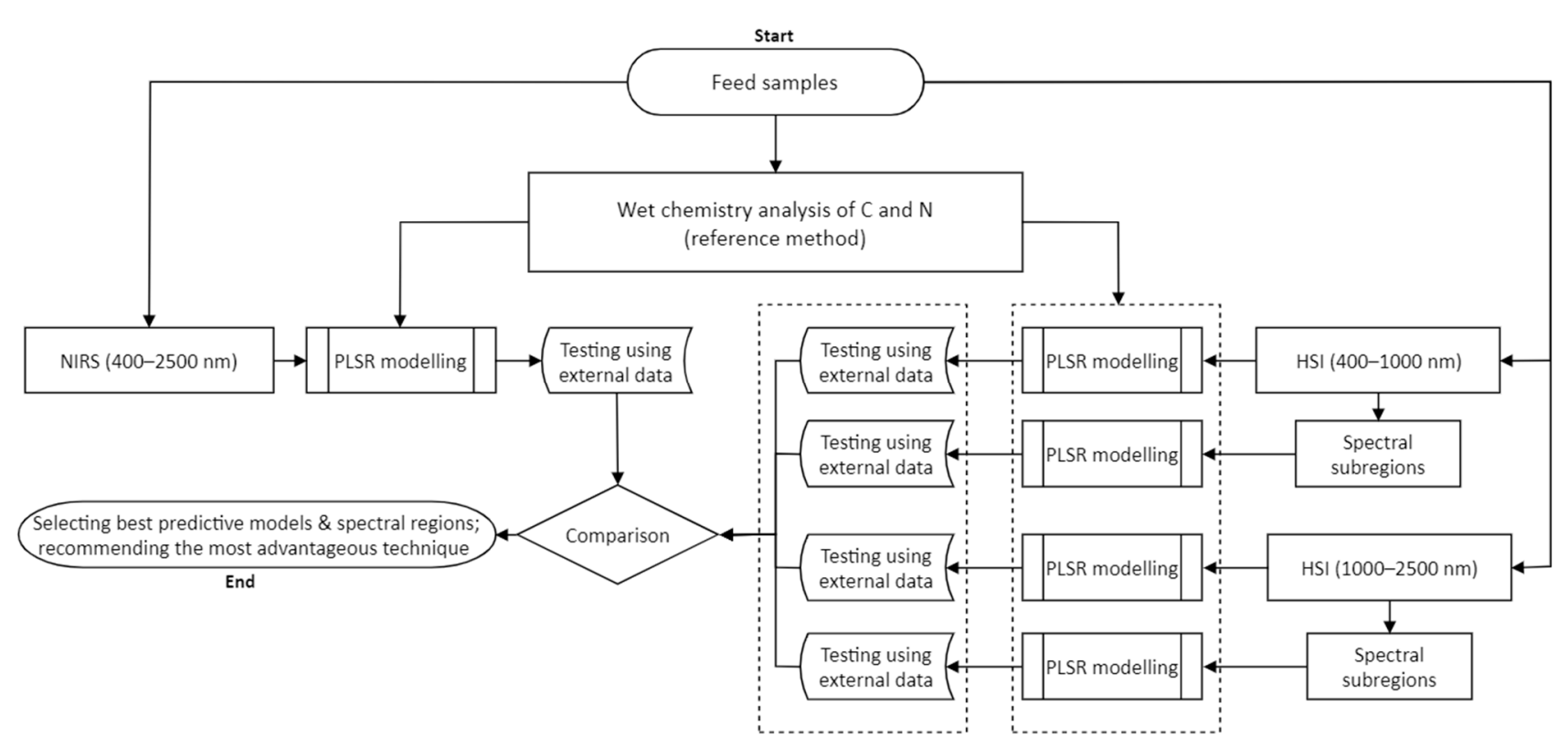

Figure 1. The procedure of near infrared spectroscopy (NIRS) and hyperspectral imaging (HSI) used for predicting carbon and nitrogen in ground wheat samples and selecting important spectral regions.

\subsection{Sample Collection, Preparation and Wet Chemistry Analysis}

Sixty-nine samples of wheat (ca. $2 \mathrm{~kg}$ ) were collected from six states of Australia including Queensland, New South Wales, Victoria, Western Australia, Tasmania and South Australia between 2016 and 2019. Each sample was a representative sample of one farmseason, collected after mixing the grains of that harvest. The samples were stored at $4{ }^{\circ} \mathrm{C}$ until analysed for $C$ and $\mathrm{N}$ concentrations in December 2019. Each $2 \mathrm{~kg}$ sample was mixed in the laboratory and a $100 \mathrm{~g}$ representative subsample was collected and ground for further analysis. A test-subsample $(0.15 \mathrm{~g})$ was selected from the ground wheat subsamples and the carbon $(\mathrm{C})$ and nitrogen $(\mathrm{N})$ concentrations were determined in the test-subsamples via a combustion analyser (Leco model FP-2000N analyser, Leco Corp.,St. Joseph, MI, USA), using ethylene diamine tetra acetic acid (EDTA) as a calibration standard [16]. Each testsubsample was analysed in triplicate and the average value of the three test-subsamples were reported for their corresponding sample. The remaining of the ground subsamples were then used for NIRS and HSI analysis.

\subsection{Spectral Analysis of the Ground Wheat Samples}

\subsubsection{Acquisition of Spectral Reflectance Using NIRS and HSI}

The ground samples were scanned using an NIRS machine (Foss NIR Systems, XDS Rapid Content Analyzer) operated in the spectral range of $400-2500 \mathrm{~nm}$ with $2 \mathrm{~nm}$ spectral sampling interval. The samples were also scanned using a visible to near infrared (VNIR) line-scanner hyperspectral camera (Resonon Pika XC 2, Bozeman, MT, USA) operated in the spectral range of 400-1000 nm with $1.3 \mathrm{~nm}$ spectral sampling interval, 1600 spatial pixels and $23.1^{\circ}$ field of view, and a shortwave infrared (SWIR) line-scanner hyperspectral camera (Hyspex SWIR-384, Oslo, Østlandet, Norway) operated in the spectral range of $1000-2500 \mathrm{~nm}$ with $5.45 \mathrm{~nm}$ spectral sampling interval, 384 spatial pixels and $16^{\circ}$ field of view (Figure 2). 

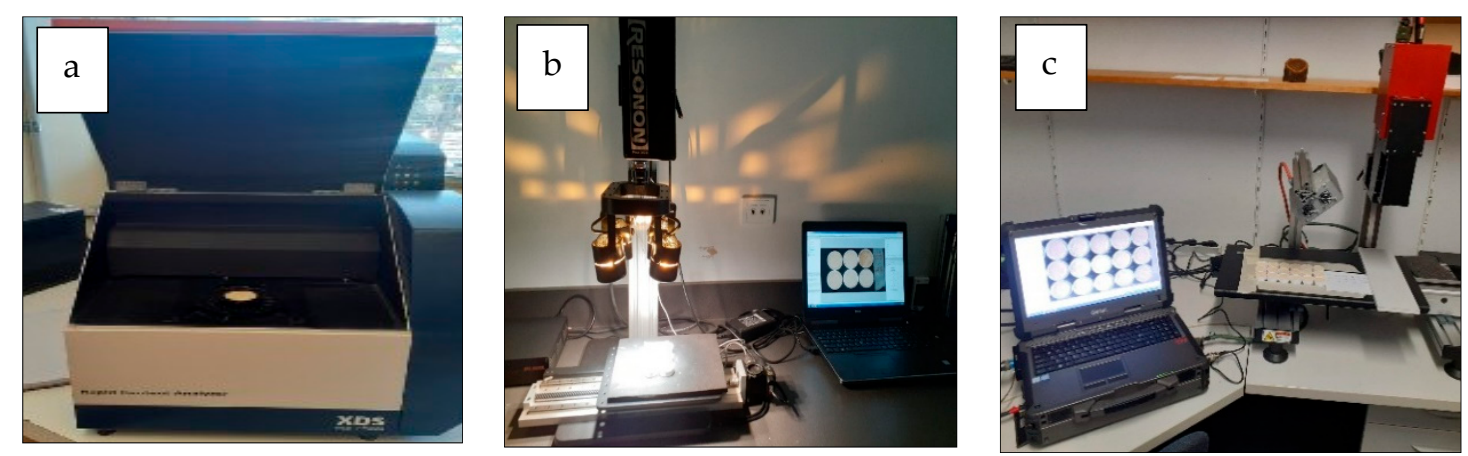

Figure 2. The near infrared spectrometer (NIRS, 400-2500 nm) (a), visible to near infrared hyperspectral imaging system (VNIR HSI, 400-1000 nm) (b) and shortwave infrared HSI system (SWIR HSI, 1000-2500 nm) (c) used in this study.

The samples were placed in the sample cell of the NIRS $(5 \mathrm{~cm}$ diameter, $1 \mathrm{~cm}$ depth), tapped 3 to 4 times, levelled, and scanned individually (one sample per run, $n=69$ runs). The time of analysis for machine adjustments, sample preparation and scanning of the 69 samples using the NIRS was approximately three hours.

For HSI scanning, the feed samples were put in plastic cups $(3 \mathrm{~cm}$ diameter cylinder, $1 \mathrm{~cm}$ depth), tapped 3 to 4 times and levelled. Then, the samples (6 samples per run, last run with 3 samples, $n=12$ runs) were placed on the translating stage of the camera and moved under the VNIR cameras field of view. The same procedure was repeated for the SWIR system (18 sample per run, last run with 15 samples, $n=4$ runs). The NIRS scans and VNIR images were captured in December 2019 and the SWIR images were captured in February 2020. The time of analysis for machine adjustments, sample preparation and scanning of the 69 samples using the VNIR and SWIR HSI was approximately one hours for each HSI system.

The samples were sealed in a plastic container and refrigerated at $4{ }^{\circ} \mathrm{C}$ between the two scanning times. To verify that this refrigeration time did not introduce a bias to the performed analysis, six test samples (see Section 2.3.3) were re-scanned using VNIR HSI in February 2020 and their spectral reflectance were compared with those scanned in 2019 (see Table S1 in Supplementary Material).

\subsubsection{Hyperspectral Image Correction and Sample Identification}

The hyperspectral images captured using the VNIR and SWIR cameras were subjected to dark and white corrections to remove the cameras' dark current and measure the relative reflectance (Equation (1)). The dark and white calibration were applied by capturing an image with the lens cap on (for the VNIR camera) and shutter closed (for the SWIR camera) prior to capturing the images from the samples and measuring the spectral reflectance of a white sheet with approximately $99 \%$ of reflectance, respectively $[17,18]$.

$$
\mathrm{R}=\left(\mathrm{R}_{0}-\mathrm{D}\right) /(\mathrm{W}-\mathrm{D})
$$

where $\mathrm{R}$ is the relative reflectance calculated for each pixel, $\mathrm{R}_{0}$ is raw reflectance measured for each pixel, $\mathrm{D}$ is dark current, and $\mathrm{W}$ is the reflectance of the white sheet.

A principal component analysis (PCA) with 6 components was used to identify the pixels of the ground wheat samples and remove the background from the hyperspectral images [19] (Figure S1 in supplementary material). The time spent for sample identification and background removal was approximately one hour for the images captured using both VNIR and SWIR HSI systems.

The average spectral reflectance of the samples (10,000-30,000 pixels per sample) were used for calibration of partial least square (PLSR) models. The PLSR is a commonly accepted machine learning algorithm used for chemometrics [20-22]. The PLSR model performs well with small, collinear and noisy data and generates independent latent variables using cross-validation which chooses the response variable from the strongest prediction [22-24]. 
Evince software package (version 2.7.11, Prediktera AB, Umeå, Västerbottens län, Sweden) and the Unscrambler software package (version 11.0, Camo Analytics AS, Oslo, Norway) were used for image processing and PLSR modelling in this study.

\subsubsection{PLSR Model Development and Evaluation}

The datasets were randomly divided into a calibration set with 63 samples and a test set with 6 samples for evaluation of the models. The calibration and test samples were the same for NIRS, VNIR and SWIR HSI systems. A $t$-test was performed to compare the calibration and the test sets, to confirm consistent coverage of the whole range of values for target variables $[25,26]$.

PLSR models were trained to correlate the spectral reflectance of the samples, measured using NIRS, VNIR and SWIR HSI cameras, with their reference C and N concentrations (measured using wet chemistry analysis) in the calibration datasets. Data transformation techniques, including Savitzky-Golay derivatives, multiple scatter corrections, orthogonal signal correction and standard normal variate, were used (individually or combined) to increase the signal to noise ratio where needed [27]. The number of latent variables (LV) for the PLSR models was selected at the lowest predicted residual error sum of squares (PRESS) in the cross-validation set (Equation (2)). A k-fold $(k=10)$ crossvalidation was used in this study [28,29]. In general, data were split into 10 sets for a 10 -fold cross-validation. In this case, the models were developed iteratively using nine sets, with one set left out for validation on each iteration. This process was repeated until all the sets were left out of the models once [29].

$$
\text { PRESS }=\sum_{i=1}^{n}\left(Y_{i}-Y_{i}\right)^{2}
$$

where $Y_{i}$ and $\hat{Y}_{i}$ are the reference and predicted values of each target variable in the $i$ th sample, respectively.

The models developed using the spectral reflectance of the samples in the calibration sets were then tested using the test sets. The accuracy of the $\mathrm{C}$ and $\mathrm{N}$ concentrations predicted using NIRS and the HSI cameras were evaluated and compared against their corresponding reference concentrations. The best models were selected based on having the highest coefficient of determination $\left(\mathrm{R}^{2}\right)$ and lowest root mean square error (RMSE) in the calibration $\left(R_{c}^{2}\right.$ and $\left.R M S E_{c}\right)$ and test sets $\left(R_{t}^{2}, R M S E_{t}\right)$ represented in Eq. 3 and 4 .

$$
\begin{gathered}
\mathrm{R}^{2}=1-\frac{\sum_{i=1}^{n}\left(\mathrm{Y}_{i}-Y_{i}\right)^{2}}{\sum_{i=1}^{n}\left(\mathrm{Y}_{i}-Y\right)^{2}} \\
\mathrm{RMSE}=\sqrt{\frac{\sum_{i=1}^{n}\left(\mathrm{Y}_{i}-Y_{i}\right)^{2}}{\mathrm{~N}}}
\end{gathered}
$$

where $Y_{i}$ and $\hat{Y}_{i}$ are the reference and predicted values of target variables $(C$ and $N)$ in the $i$ th sample, respectively. The $\bar{Y}$ is the mean of reference values and $N$ is the number of samples.

The ratio of performance to deviation (RPD), represented in Equation (5), was also used to further evaluate the performance of the models $[30,31]$.

$$
\mathrm{RPD}=\frac{\mathrm{SD}_{t}}{\mathrm{RMSE}_{t}}
$$

where $\mathrm{SD}_{t}$ is the standard deviation of the reference values in the test sets and $\mathrm{RMSE}_{t}$ is the root mean square error of the prediction in the test set.

The models that provided RPD > 1.4 for the predictions were considered as "good" and those with RPD > 2 were considered as "excellent" [32]. 
To illustrate the spatial distribution of the $\mathrm{C}$ and $\mathrm{N}$ concentrations, PLSR models developed using hyperspectral images were used to predict $C$ and $N$ in individual pixels and the variations were represented using colour codes.

\subsubsection{Identification of the Important Spectral Regions}

In this study, the spectra measured by the VNIR and SWIR cameras were divided into multiple subregions (every $150 \mathrm{~nm}$ ) and a separate PLSR model was developed using the data of each spectral subregion. This was conducted to identify the most important spectral subregions that can be measured using affordable multispectral cameras available in the market or can be developed using the available hardware. We did not use common band-selection techniques (e.g., stepwise, $\beta$-coefficient, partial swarm optimization) in this study as these methods usually select important wavelengths from all the measured electromagnetic spectra (here $400-2500 \mathrm{~nm}$ ) whereas multispectral cameras mainly measure narrow bands in VNIR or SWIR regions depending on their sensors. Suitable data transformation techniques (including Savitzky-Golay derivatives, multiple scatter corrections, orthogonal signal correction and standard normal variate) were applied to increase the signal to noise ratio in the subregions where needed. The modelling and evaluation procedures were similar to those explained in Section 2.3.3.

\section{Results}

\subsection{Descriptive Analysis}

The average $\mathrm{C}$ and $\mathrm{N}$ concentrations in the calibration set (measured using wet chemistry) were $40.64 \%$ and $1.84 \%$ and those in the test set were $40.88 \%$ and $1.88 \%$, respectively (Table 1). There were no significant differences $(p<0.05)$ between the means in the calibration and test sets. The coefficient of variations was smaller for $\mathrm{C}$ compared to that of $\mathrm{N}$ with $1.61 \%$ vs. $13.16 \%$ in the calibration set and $1.17 \%$ vs. $13.07 \%$ in the test set (Table 1 ), respectively.

Table 1. Descriptive analysis measured using wet chemistry analysis.

\begin{tabular}{ccccc}
\hline & \multicolumn{2}{c}{ Calibration (63 Samples) } & \multicolumn{2}{c}{ Test (6 Samples) } \\
\hline & $\mathbf{C ~ ( \% )}$ & $\mathbf{N ~ ( \% )}$ & $\mathbf{C ~ ( \% )}$ & $\mathbf{N ~ ( \% )}$ \\
\hline Mean & 40.64 & 1.84 & 40.88 & 1.88 \\
Min & 38.89 & 1.45 & 40.11 & 1.61 \\
Max & 41.49 & 2.61 & 41.59 & 2.22 \\
Range & 2.60 & 1.16 & 1.48 & 0.61 \\
SD & 0.65 & 0.24 & 0.48 & 0.25 \\
Coefficient of & 1.61 & 13.16 & 1.17 & 13.07 \\
variations & & & & \\
\hline
\end{tabular}

Min is minimum, max is maximum, SD is standard deviation.

\subsection{Spectral Features}

As expected, the average reflectance measured using the HSI cameras were similar to their corresponding spectral region measured using NIRS (Figure 3). The average reflectance generally increased in the VNIR region after a downward peak at $400-415 \mathrm{~nm}$; and then decreased in the SWIR region to its minimum at $2500 \mathrm{~nm}$. There were more absorption/reflection peaks in the SWIR region compared to the VNIR region, with two major reductions in reflectance around $1460 \mathrm{~nm}$ and $1930 \mathrm{~nm}$. 


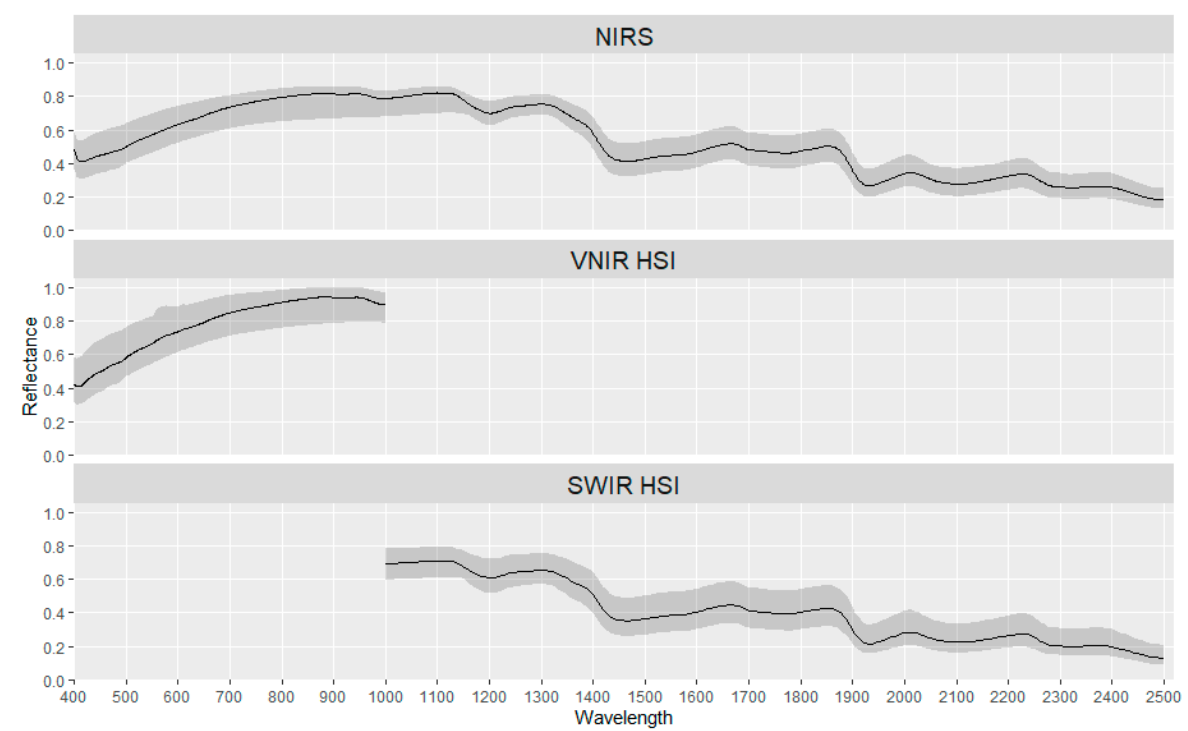

Figure 3. Relative spectral reflectance of the feed samples measured using the near infrared spectroscopy (NIRS, 400$2500 \mathrm{~nm}$ ) (Top), visible to near infrared hyperspectral imaging (VNIR HSI, 400-1000 nm) (middle) and shortwave infrared HSI (SWIR HSI, 1000-2500 nm) (bottom). Solid line is the average of 69 samples and shading shows the range.

\subsection{Attributes of the Models and Comparing Prediction Accuracies of PLSR Models}

The models developed using the NIRS and the HSI cameras for predicting $\mathrm{C}$ and $\mathrm{N}$ in feed samples had 1 to $13 \mathrm{LV}$ (Tables 2 and 3 ). The highest accuracy for the majority of models was achieved using the non-transformed data, while in some models, orthogonal signal correction (OSC) and detrending (DT) increased the signal to noise ratio and improved model accuracy (Tables 2 and 3).

Table 2. Attributes of the PLSR models developed for predicting carbon (C) in the calibration and test sets.

\begin{tabular}{|c|c|c|c|c|c|c|c|c|c|c|}
\hline & WL (nm) & LV & TF & $\mathbf{R}^{2}$ cal & $\mathrm{R}^{2} \mathrm{CV}$ & $\begin{array}{l}\text { RMSE } \\
\text { cal (\%) }\end{array}$ & $\begin{array}{l}\text { RMSE } \\
\text { CV (\%) }\end{array}$ & Test $\mathbf{R}^{2}$ & $\begin{array}{c}\text { Test } \\
\text { RMSE }\end{array}$ & RPD \\
\hline NIRS & $400-2500$ & 4 & - & 0.90 & 0.89 & 0.20 & 0.22 & 0.84 & 0.23 & 1.88 \\
\hline VNIR camera & 400-1000 & 7 & OSC & 0.97 & 0.90 & 0.12 & 0.22 & 0.89 & 0.18 & 2.39 \\
\hline SWIR camera & $1000-2515$ & 7 & OSC, DT & 0.80 & 0.80 & 0.29 & 0.30 & 0.86 & 0.23 & 1.89 \\
\hline \multirow{4}{*}{ VNIR camera } & $400-550$ & 5 & OSC & 0.93 & 0.78 & 0.17 & 0.31 & 0.86 & 0.21 & 2.03 \\
\hline & $551-700$ & 8 & - & 0.50 & 0.16 & 0.45 & 0.57 & 0.56 & 0.31 & 1.39 \\
\hline & $701-850$ & 4 & - & 0.26 & 0.08 & 0.55 & 0.62 & 0.40 & 0.34 & 1.30 \\
\hline & $851-1000$ & 5 & - & 0.64 & 0.48 & 0.38 & 0.47 & 0.45 & 0.39 & 1.13 \\
\hline \multirow{10}{*}{ SWIR camera } & $1000-1150$ & 1 & OSC & 0.68 & 0.68 & 0.37 & 0.38 & 0.46 & 0.40 & 1.09 \\
\hline & $1151-1300$ & 7 & - & 0.60 & 0.34 & 0.41 & 0.53 & 0.41 & 0.47 & 0.92 \\
\hline & $1301-1450$ & 1 & OSC & 0.69 & 0.69 & 0.36 & 0.37 & 0.29 & 0.43 & 1.01 \\
\hline & $1451-1600$ & 1 & OSC & 0.72 & 0.74 & 0.34 & 0.35 & 0.80 & 0.34 & 1.52 \\
\hline & $1601-1750$ & 6 & - & 0.63 & 0.43 & 0.39 & 0.51 & 0.40 & 0.42 & 1.04 \\
\hline & $1751-1900$ & 3 & - & 0.65 & 0.61 & 0.38 & 0.42 & 0.41 & 0.43 & 1.02 \\
\hline & 1901-2050 & 2 & - & 0.66 & 0.62 & 0.38 & 0.40 & 0.33 & 0.45 & 0.97 \\
\hline & $2051-2200$ & 4 & - & 0.63 & 0.54 & 0.39 & 0.44 & 0.00 & 0.00 & 0.00 \\
\hline & $2201-2350$ & 5 & - & 0.55 & 0.28 & 0.43 & 0.56 & 0.41 & 0.48 & 0.91 \\
\hline & $2351-2515$ & 5 & - & 0.73 & 0.64 & 0.34 & 0.39 & 0.35 & 0.41 & 1.04 \\
\hline
\end{tabular}

$\mathrm{WL}$ is wavelength; $\mathrm{LV}$ is latent variable number; TF is transformation technique; cal is calibration; CV is cross-validation; RMSE is root mean square error; $\mathrm{R}^{2}$ is coefficient of determination; RPD is ratio of performance to deviation; OSC is orthogonal signal correction; DT is detrend. 
Table 3. Attributes of the PLSR models developed for predicting nitrogen $(\mathrm{N})$ in the calibration and test sets.

\begin{tabular}{cccccccccccc}
\hline & WL (nm) & LV & TF & $\mathbf{R}^{\mathbf{2}}$ cal & $\mathbf{R}^{\mathbf{2}} \mathbf{C V}$ & $\begin{array}{c}\text { RMSE } \\
\text { cal (\%) }\end{array}$ & $\begin{array}{c}\text { RMSE } \\
\text { CV (\%) }\end{array}$ & Test R $\mathbf{R}^{\mathbf{2}}$ & $\begin{array}{c}\text { Test } \\
\text { RMSE }\end{array}$ & RPD \\
\hline NIRS & $400-2500$ & 10 & - & 0.96 & 0.92 & 0.05 & 0.07 & 0.99 & 0.05 & 4.63 \\
VNIR camera & $400-1000$ & 13 & - & 0.80 & 0.33 & 0.11 & 0.21 & 0.91 & 0.09 & 2.56 \\
SWIR camera & $1000-2515$ & 8 & - & 0.97 & 0.94 & 0.04 & 0.06 & 0.99 & 0.04 & 5.15 \\
\hline & $400-550$ & 1 & - & 0.0 & 0.0 & 0.0 & 0.0 & NC & NC & NC \\
VNIR camera & $551-700$ & 1 & - & 0.0 & 0.0 & 0.0 & 0.0 & NC & NC & NC \\
& $701-850$ & 2 & - & 0.1 & 0.06 & 0.23 & 0.24 & NC & NC & NC \\
& $851-1000$ & 6 & OSC & 0.68 & 0.71 & 0.09 & 0.13 & 0.30 & 0.19 & 1.18 \\
\hline & $1000-1150$ & 8 & - & 0.82 & 0.70 & 0.10 & 0.13 & 0.93 & 0.06 & 3.14 \\
& $1151-1300$ & 8 & - & 0.93 & 0.88 & 0.06 & 0.08 & 0.93 & 0.11 & 2.07 \\
& $1301-1450$ & 6 & - & 0.55 & 0.39 & 0.16 & 0.19 & 0.95 & 0.07 & 3.08 \\
& $1451-1600$ & 6 & - & 0.91 & 0.89 & 0.07 & 0.08 & 0.99 & 0.06 & 3.80 \\
& $1601-1750$ & 6 & - & 0.92 & 0.85 & 0.07 & 0.09 & 0.83 & 0.11 & 2.11 \\
& $1751-1900$ & 7 & - & 0.87 & 0.78 & 0.08 & 0.12 & 0.88 & 0.10 & 2.33 \\
& $1901-2050$ & 6 & - & 0.92 & 0.89 & 0.07 & 0.08 & 0.96 & 0.06 & 3.47 \\
& $2051-2200$ & 5 & - & 0.92 & 0.87 & 0.06 & 0.07 & 0.95 & 0.06 & 3.52 \\
& $2201-2350$ & 6 & - & 0.81 & 0.72 & 0.10 & 0.13 & 0.71 & 0.13 & 1.70 \\
& $2351-2515$ & 3 & - & 0.36 & 0.30 & 0.19 & 0.20 & 0.21 & 0.21 & 1.06 \\
\hline
\end{tabular}

WL is wavelength; LV is latent variable number; TF is transformation method; cal is calibration; CV is cross-validation; RMSE is root mean square error; $\mathrm{R}^{2}$ is coefficient of determination; RPD is ratio of performance to deviation; NC is not checked, OSC is orthogonal signal correction.

The VNIR hyperspectral camera provided the most accurate predictions of $C$, as demonstrated by the highest $\mathrm{R}^{2}$ and lowest RMSE values in the calibration and test sets, and the highest RPD in the test sets (Table 2; Figure 4). For N, the SWIR hyperspectral camera provided the most accurate prediction based on the same statistical measures (Table 3; Figure 5). The spatial distribution of the $\mathrm{C}$ and $\mathrm{N}$ in the test samples are represented in Figure 6.

\subsection{Important Spectral Regions for Predicting C and N Using Hyperspectral Cameras}

Spectral subregions, represented in Tables 2 and 3, were used to develop PLSR models for predicting $\mathrm{C}$ and $\mathrm{N}$ concentrations in feed samples to identify the most important spectral regions. The best $C$ predictions were achieved in $400-550 \mathrm{~nm}$, as demonstrated by the highest $R^{2}$ and lowest RMSE values in the calibration and test sets, and the highest RPD in the test sets (Table 2). The spectral region of 1451-1600 nm was also important for predicting $\mathrm{C}$ in the feed samples (Table 2). The most important spectral regions for predicting $\mathrm{N}$ concentrations in the feed samples included 1451-1600 nm, 1901-2050 nm and 2051-2200 nm (Table 3). 


\section{NIRS}
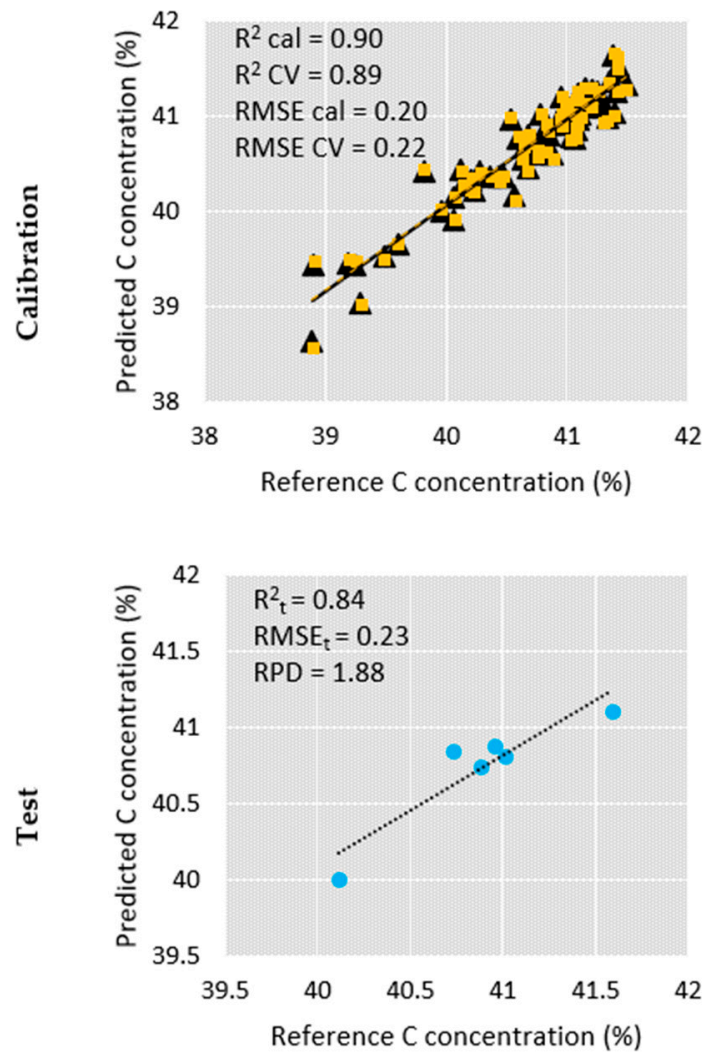

VNIR HSI
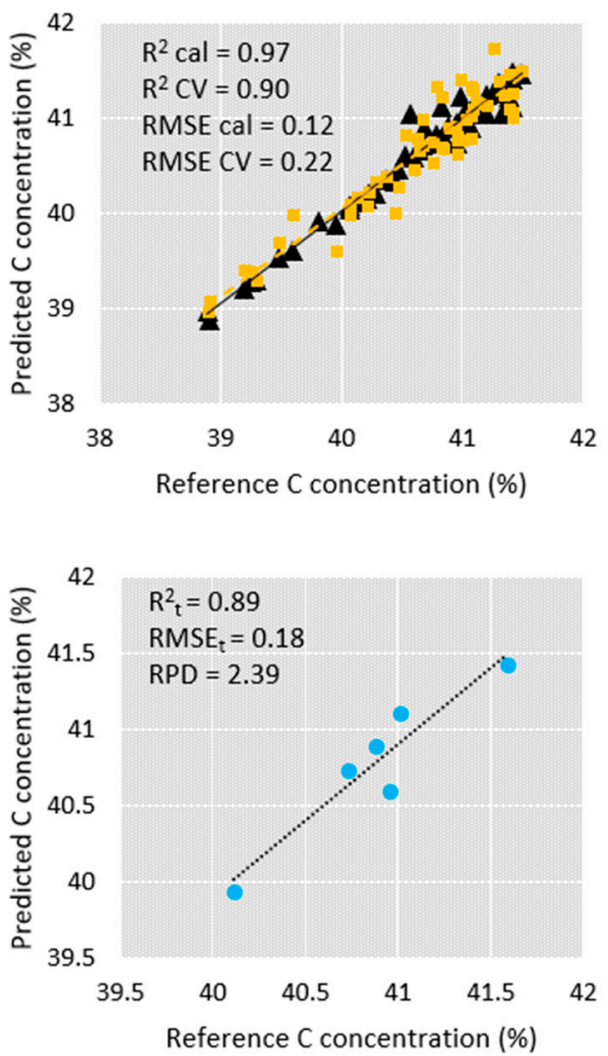

\section{SWIR HSI}
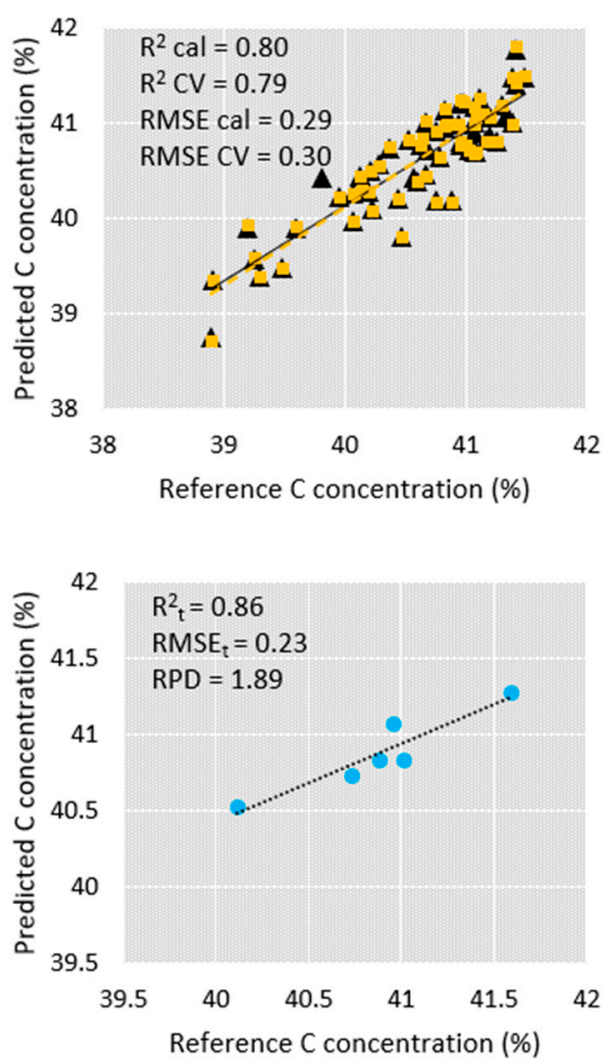

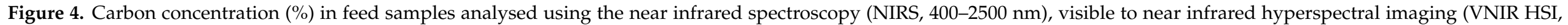

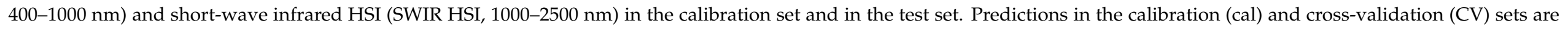
presented in close triangles (solid lines) and squares (dashed lines), respectively. Predictions in the test set $(\mathrm{t})$ are presented in close circles (dotted line). 


\section{NIRS}
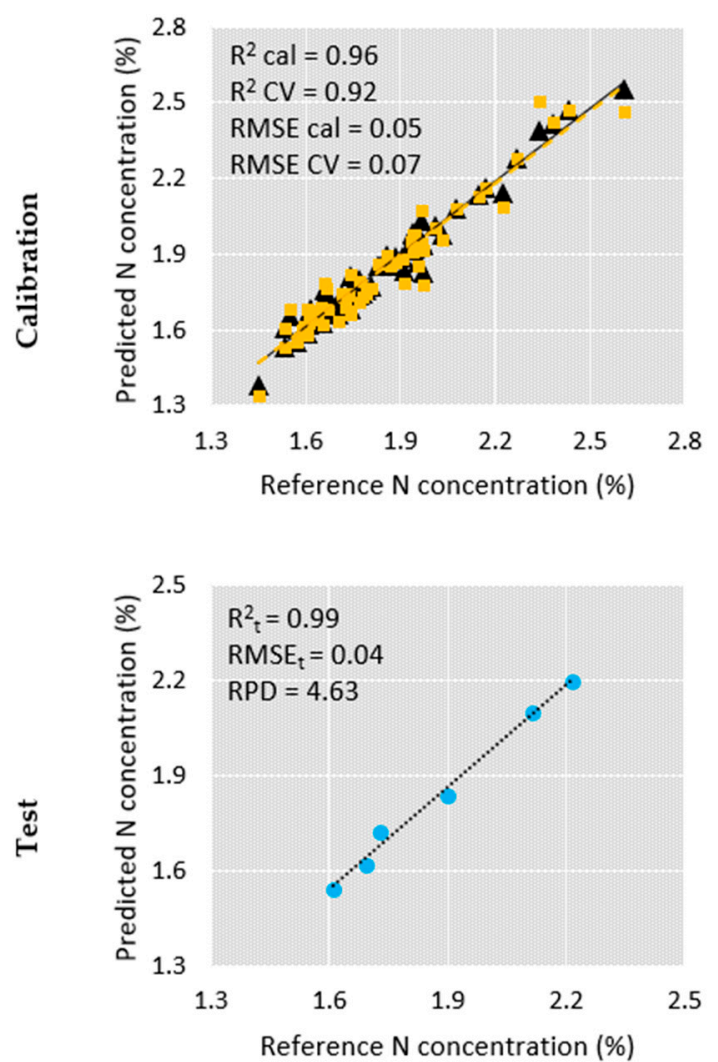

VNIR HSI
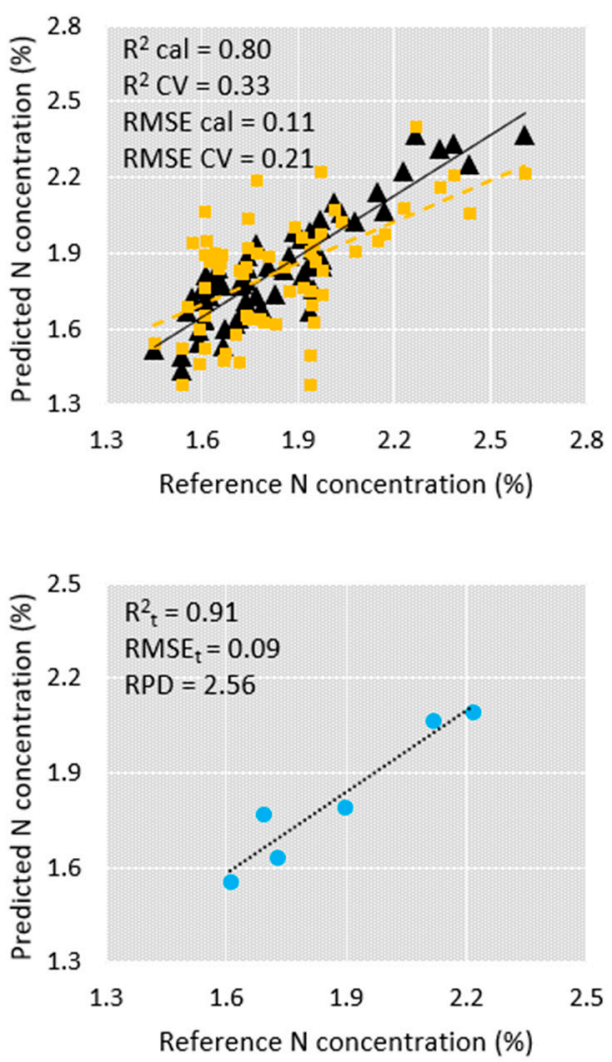

\section{SWIR HSI}
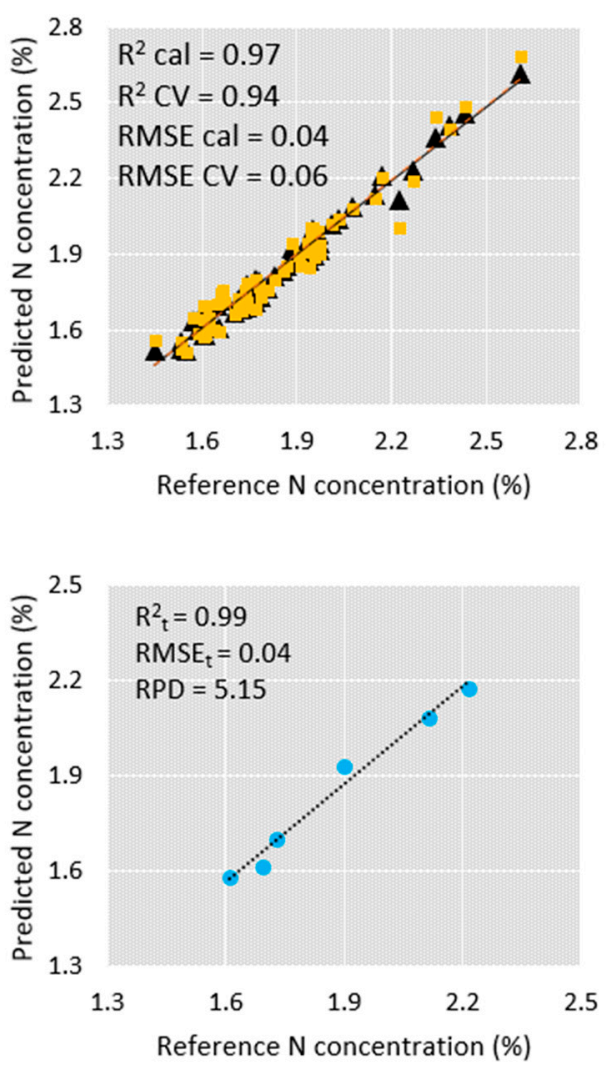

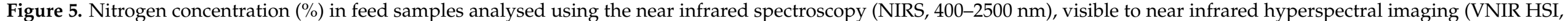

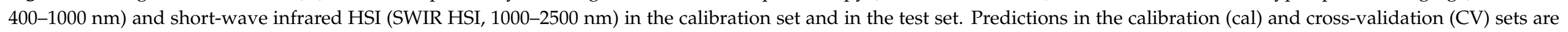
presented in close triangles (solid lines) and squares (dashed lines), respectively. Predictions in the test set $(t)$ are presented in close circles (dotted line). 
RGB image of the samples

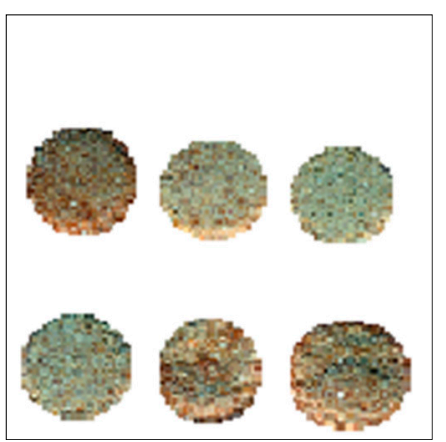

Carbon concentration (\%)

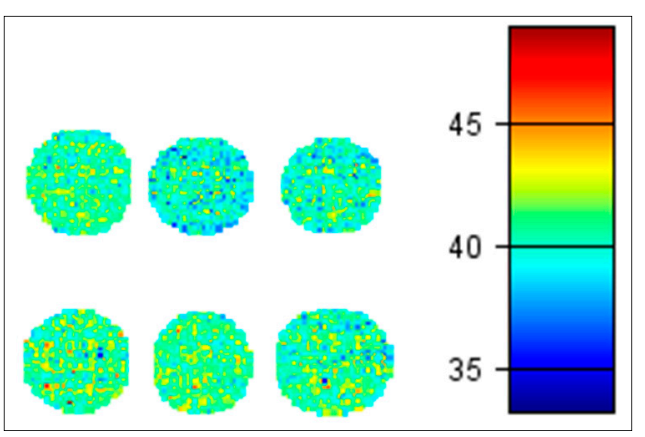

Nitrogen concentration (\%)

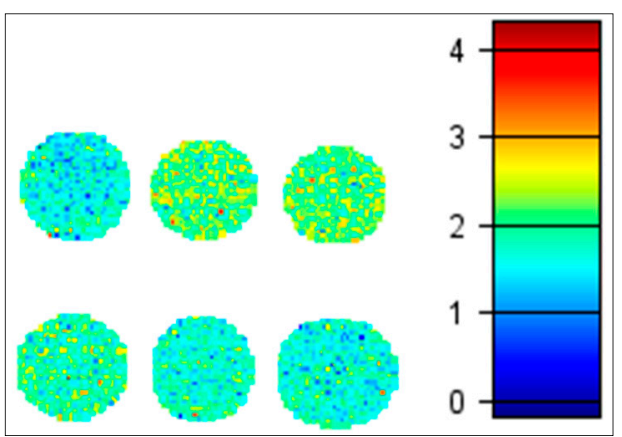

Figure 6. Spatial distribution of carbon $(\mathrm{C})$ and nitrogen $(\mathrm{N})$ concentrations in the test feed samples predicted using full wavelengths of shortwave infrared (SWRI) data. The images were cropped from the original images and the texts in the images were improved for better resolution. The original image is represented in Supplementary Material Figure S2.

\section{Discussion}

\subsection{Technical}

In this study, NIRS (400-2500 nm) and HSI technology (400-1000 nm and 1000$2500 \mathrm{~nm}$ ) were compared for predicting $\mathrm{C}$ and $\mathrm{N}$ concentrations in feed (ground wheat) samples. While HSI used limited spectral range (either 400-1000 nm or 1000-2500 nm) compared to NIRS (400-2500 nm), the accuracy of the HSI predictions was similar to or better than NIRS. The calibration processes of the models were the same, and the best predictive models were selected for each instrument; however, the models developed using the HSI data had more information per sample to be trained with. This means that for each average value of $\mathrm{C}$ and $\mathrm{N}$ (per sample), measured using the wet chemistry methods, there were ca. 10,000-30,000 detection points (large statistical population) in HSI and only 1 detection point in NIRS. In other words, HSI can reveal more variation/deviations from the average value related to one sample compared to NIRS. This provides users of HSI with a benefit of more efficient and faster calibration and might be the reason why, in this study, HSI performed as well as or even better than NIRS. Our study is consistent with other studies. For example, protein contents in wheat flour were predicted with similar or more prediction accuracy when two classical NIRS (NIR-DS and NIR-Perstop, 400-2498 nm) and a SWIR hyperspectral camera (1128-2425 nm) were compared [33]. The protein and nitrogen concentrations are highly correlated and therefore their results are comparable to our N predictions [34-36]. Burger and Geladi [37] also compared NIRS and HSI in the SWIR region for studying organic and biological samples (i.e., cheese and artificial mixtures of pure constituents). They used a median spectrum form hyperspectral images (median of ROI in one image) and compared them with the same wavelengths and resolution measured using NIRS, reporting comparable results.

The most informative spectral region for predicting $C$ concentrations in the ground wheat samples was 400-550 nm, measured using VNIR HSI camera. Limited information is available on predicting wheat flour C concentrations using NIRS or HSI systems, however, this spectral region is reported to be important for $\mathrm{C}$ prediction in soil and plant tissues [38-41]. Generally, the reflectance/absorbance at 400-550 $\mathrm{nm}$ has been attributed to electronic transitions associated with chlorophyll $a$ and $b$ [42]. For example, Datt [43] showed that the reflectance at $550 \mathrm{~nm}$ was sensitive to the variations in chlorophyll-a pigment in the leaves of various Eucalyptus species. Carbon constitutes a great proportion (over $70 \%$ ) of chlorophyll molecular weight and this might explain why our best predictions of the ground wheat $C$ concertation were achieved at 400-550 nm. The $C$ concentrations could also be predicted, with lower accuracy, in 1451-1600 nm, possibility due to the $\mathrm{C}-\mathrm{H}$ stretch and $\mathrm{C}-\mathrm{H}$ deformation at this spectral region [42]. 
The best $\mathrm{N}$ predictions were achieved at 1451-1600 $\mathrm{nm}$ while $\mathrm{N}$ could also be predicted in 1900-2050 nm and 2051-2200 nm spectral ranges. It has been reported that N-H stretch and first overtone occurs at $1510 \mathrm{~nm}$, attributed to protein and $\mathrm{N}$ [42], falling within 1451-1600 nm subregion in this study. Also, the second overtone, $\mathrm{N}=\mathrm{H}$ and $\mathrm{N}-\mathrm{H}$ bend, and $\mathrm{N}-\mathrm{H}$ and C-N stretch occur in 1900-2200 $\mathrm{nm}[42,44]$, which is consistent with our finding in 1900-2050 $\mathrm{nm}$ and 2051-2200 nm. Other studies also reported similar spectral regions for protein-N predictions in wheat samples [45,46]. For example, Salgo and Gergely [45] reported that the absorption in 2055-2060 $\mathrm{nm}$ and 2175-2180 $\mathrm{nm}$ are related to the changes in protein contents (highly correlated with $\mathrm{N}$ ).

\subsection{Application}

This study has demonstrated that HSI is as accurate, or more accurate, than NIRS scanning technology. Importantly, the capability for HSI to scan thousands to millions of pixels within an image provides an advantage over NIRS which scans just one point. For example, HSI allows the surface of an entire sample to be scanned, giving us a greater understanding of the variation that exists within feed ingredients, and the ability for the technology to be used to continuously analyse samples in a continuous production process, such as a feed mill. This larger and more thorough collection of data also means that development of HSI calibrations should be faster due to the greater statistical information that may be generated from each sample; whereas, NIRS relies on the false assumption that a sample will be homogenous throughout and/or samples are representative of the entire load. Thus, identification of a compositional gradient via HSI is advantageous to animal feed processors as it may analyse the entirety of a delivery of grain if the HSI system is placed in-line as the grain is augured off a truck, or at the end of the pelletizer to ensure the final pelleted diet meets the required specifications, and nutrients within the pelleted ration are uniformly distributed. The application of the HSI in feed mills needs engineering design and modification in the feed mills and need to be studied further in future research.

In this study, HSI was able to recognize and visualise the variabilities between and within the samples. The variabilities between the samples could be caused by different geographical or seasonal variations and the variabilities within the samples might have been caused by impurities, such as wheat stubble. The samples used in this study were homogenised and ground, whereas, in practice, this may not be feasible; and therefore, more variabilities would exist within the samples that are not detectable using NIRS. This may result in over or underestimating of the concentration of nutrients that could be predicted more accurately using HSI.

The ability to collect data on the distribution of nutrients within a feed grain or a final pelleted feed, and get a more accurate determination of the variability that may exist within ingredients and final pellet diets is of great economic importance for the poultry industries. In the chicken meat industry, the economic impact of variability of crude protein (nitrogen $\times 6.25$ ) in diets has been modelled [47]. Within this analysis, wheat was identified to be the single greatest source of variability in the crude protein content of a standard meat chicken diet [47]. This is concerning as wheat is the most used feed ingredient for poultry in Australia. Moss et al. [47] calculated that the over-estimation of nutrient contents and variability of crude protein in feedstuffs could result in a reduction of profits of up to $\$ 26,753$ in gross margin from one cycle of 30,000 meat chickens. In addition to the economic burden, $\mathrm{N}$ may be overfed when $\mathrm{N}$ content of the feed ingredients is under-estimated [48]. Over supply of $\mathrm{N}$ may potentially contribute to an increase in excreted uric acid, which is known to be a pre-curser to ammonia production, and this may contribute to higher ammonia concentrations in the poultry house [49,50]. Additionally, within the egg industry, it was determined that standard layer diets formulated to $0.48 \%$ true digestible dietary methionine levels had approximately a 1 in 20 chance of formulating a diet with $<0.3 \%$ true digestible methionine due to the variability that exists within the methionine content of Australian feed ingredients [50]. The profitability of a flock of 20,000 hens over a 6-week period may be reduced by $\$ 51,309$ if the diet falls below $0.3 \%$ true digestible methionine. 
Hence, the data on the distribution of nutrients collected by HSI, and the ability of HSI to get a more accurate determination of the variability that may exists within a feed grain or a final pelleted feed, may be economically important for poultry industries.

HSI systems may be a significant investment to set up, but they are a multifunctional instrument [33], and as demonstrated in the present study, the most important spectral region required may be selected using hyperspectral cameras, and then the actual measurements are conducted with more affordable multispectral cameras that focus on the identified spectra only. Another advantage of HSI is its ability to identify objects and compatibility with machine vision. These applications have led to its use within quality assurance and poultry processing plants [14,15], and this use may also be extended to the feed mill. Examples include (a) identifying to what extent nutrients are evenly distributed throughout a feed batch and thereby identifying mixing issues, (b) detecting the level of mycotoxin or other contaminates of a feed ingredient, and (c) detecting extraneous objects in products at feed mills or poultry processing plants.

\section{Conclusions}

The results of this study showed that the HSI technology is as accurate as NIRS for predicting $C$ and $N$ in ground wheat samples. The concentration of $C$ and $N$ could be predicted, with high accuracy, using the reflectance at 400-550 nm, for $C$, and either $1451-1600 \mathrm{~nm}, 1901-2050 \mathrm{~nm}$ or $2051-2200 \mathrm{~nm}$ for N. These narrow wavebands can be measured using multispectral cameras that are more affordable compared to HSI cameras. The spatial dimension of HSI, also, poses many advantages and potential applications in data collection and quality assurance within feed mills to scan both ingredients and pelleted feeds, and within poultry processing plants.

Thus, the HSI technology can potentially contribute to economic benefits for the poultry industries, and potentially other intensive animal industries, and this technology warrants further consideration for integration into feed mills and processing plants. This study was a preliminary investigation and more research and samples are required to implement hyperspectral/multispectral imaging technology to the Australian poultry industries and generate reliable predictions of the protein, fat, fibre, ash, starch and amino acid content of common Australian feed ingredients. We also suggest comparing data collection methods to investigate whether the samples should be analysed as they are collected, or if they can be stored for batch processing later.

Supplementary Materials: The following are available online at https:/ / www.mdpi.com/2072-429 2/13/6/1128/s1, Figure S1. Principle component analysis (PCA) of the reflectance measured using shortwave infrared (SWIR) hyperspectral imaging (HSI) system. The figure has been created using Evince software (version 2.7.11) and labelled in Microsoft Paint, Figure S2. Spatial distribution of carbon $(\mathrm{C})$ and nitrogen $(\mathrm{N})$ concentrations in the test feed samples predicted using full wavelengths of shortwave infrared (SWIR) hyperspectral imaging data, and Table S1. Comparing the spectral reflectance of six test samples captured using the visible to near infrared hyperspectral imaging (VNIR HSI, 400-1000 nm) system in December 2019 (before) and February 2020 (after). This test was conducted to verify that refrigeration period between scanning the samples with VNIR HSI in December 2019 and shortwave infrared (SWIR) HSI in February 2020 did not introduce a bias to the preformed analysis.

Author Contributions: Conceptualization, I.T., N.K.M., S.H.B., M.W.D. and A.F.M.; Investigation, I.T., N.K.M. and A.F.M.; Methodology, I.T., S.H.B., M.W.D. and A.F.M.; Resources, I.T., N.K.M., S.H.B., M.W.D. and A.F.M.; Visualization, I.T.; Writing-original draft, I.T. and A.F.M.; Writing-review \& editing, N.K.M., S.H.B. and M.W.D. All authors have read and agreed to the published version of the manuscript.

Funding: This research received no external funding.

Institutional Review Board Statement: Not applicable.

Informed Consent Statement: Not applicable. 
Data Availability Statement: The data that support the findings of this study are available from the corresponding author, upon reasonable request.

Acknowledgments: This research has been supported by the Department of Agriculture and Fisheries (DAF), Queensland Government, the University of New England, Armidale, and Griffith University, Nathan. The authors also thank Michael Farrar for facilitating access to the VNIR HSI system at Griffith University and Naiomi Metzroth, DAF, for facilitating access to the NIR spectrometer.

Conflicts of Interest: The authors declare no conflict of interest.

\section{References}

1. Wilkinson, S. Big Data for Poultry-What Is Possible? In Proceedings of the 29th Annual Australian Poultry Science Symposium, Sydney, Australia, 4-7 February 2018; p. 152. Available online: https://poultry-research.sydney.edu.au/publications/.

2. Moss, A.F.; Chrystal, P.V.; Cadogan, D.J.; Wilkinson, S.J.; Crowley, T.M.; Choct, M. Precision feeding and precision nutrition: A paradigm shift in broiler feed formulation? Anim. Biosci. 2021, 34, 354-362. [CrossRef]

3. ACMF. Australian Industry Facts \& Figures. Available online: https://www.chicken.org.au/facts-and-figures/ (accessed on 10 February 2020).

4. Manley, M. Near-infrared spectroscopy and hyperspectral imaging: Non-destructive analysis of biological materials. Chem. Soc. Rev. 2014, 43, 8200-8214. [CrossRef]

5. Kleyn, R. Chicken Nutrition: A Guide for Nutritionists and Poultry Professionals; Context: Leicestershire, UK, 2013.

6. Moss, A.; Crowley, T.; Choct, M. Compilation and Assessment of the Variability of Nutrient Specifications for Commonly Used Australian Feed Ingredients. Proceedings the Australian Poultry Science Symposium, Sydney, Australia,, 16-19 February 2020.

7. Tahmasbian, I.; Wallace, H.M.; Gama, T.; Hosseini Bai, S. An automated non-destructive prediction of peroxide value and free fatty acid level in mixed nut samples. LWT 2021, 143, 110893. [CrossRef]

8. Khamsopha, D.; Woranitta, S.; Teerachaichayut, S. Utilizing near infrared hyperspectral imaging for quantitatively predicting adulteration in tapioca starch. Food Control 2021, 123, 107781. [CrossRef]

9. Hu, N.; Li, W.; Du, C.; Zhang, Z.; Gao, Y.; Sun, Z.; Yang, L.; Yu, K.; Zhang, Y.; Wang, Z. Predicting micronutrients of wheat using hyperspectral imaging. Food Chem. 2021, 343, 128473. [CrossRef] [PubMed]

10. Han, Y.; Liu, Z.; Khoshelham, K.; Bai, S.H. Quality estimation of nuts using deep learning classification of hyperspectral imagery. Comput. Electron. Agric. 2021, 180, 105868. [CrossRef]

11. Sun, D.-W. Hyperspectral Imaging for Food Quality Analysis and Control; Elsevier: Amsterdam, The Netherlands, 2010.

12. Elmasry, G.; Kamruzzaman, M.; Sun, D.-W.; Allen, P. Principles and applications of hyperspectral imaging in quality evaluation of agro-food products: A review. Crit. Rev. Food Sci. Nutr. 2012, 52, 999-1023. [CrossRef]

13. Adão, T.; Hruška, J.; Pádua, L.; Bessa, J.; Peres, E.; Morais, R.; Sousa, J. Hyperspectral Imaging: A Review on UAV-Based Sensors, Data Processing and Applications for Agriculture and Forestry. Remote Sens. 2017, 9, 1110. [CrossRef]

14. Eady, M.; Setia, G.; Park, B. Detection of Salmonella from chicken rinsate with visible/near-infrared hyperspectral microscope imaging compared against RT-PCR. Talanta 2019, 195, 313-319. [CrossRef]

15. Lawrence, K.; Park, B.; Windham, W.; Mao, C. Calibration of a pushbroom hyperspectral imaging system for agricultural inspection. Trans. ASAE 2003, 46, 513. [CrossRef]

16. Casada, M.; OBrien, K. Accuracy and repeatability of protein content measurements for wheat during storage. Appl. Eng. Agric. 2003, 19, 203. [CrossRef]

17. Tahmasbian, I.; Hosseini Bai, S.; Wang, Y.; Boyd, S.; Zhou, J.; Esmaeilani, R.; Xu, Z. Using laboratory-based hyperspectral imaging method to determine carbon functional group distributions in decomposing forest litterfall. Catena 2018, 167, 18-27. [CrossRef]

18. Bai, S.H.; Tahmasbian, I.; Zhou, J.; Nevenimo, T.; Hannet, G.; Walton, D.; Randall, B.; Gama, T.; Wallace, H.M. A non-destructive determination of peroxide values, total nitrogen and mineral nutrients in an edible tree nut using hyperspectral imaging. Comput. Electron. Agric. 2018, 151, 492-500. [CrossRef]

19. Da Conceição, R.R.P.; Simeone, M.L.F.; Queiroz, V.A.V.; De Medeiros, E.P.; De Araújo, J.B.; Coutinho, W.M.; Da Silva, D.D.; De Araújo Miguel, R.; De Paula Lana, U.G.; De Resende Stoianoff, M.A. Application of near-infrared hyperspectral (NIR) images combined with multivariate image analysis in the differentiation of two mycotoxicogenic Fusarium species associated with maize. Food Chem. 2021, 344, 128615. [CrossRef] [PubMed]

20. Fu, Y.; Yang, G.; Song, X.; Li, Z.; Xu, X.; Feng, H.; Zhao, C. Improved Estimation of Winter Wheat Aboveground Biomass Using Multiscale Textures Extracted from UAV-Based Digital Images and Hyperspectral Feature Analysis. Remote Sens. 2021, 13, 581. [CrossRef]

21. Xu, X.; Fan, L.; Li, Z.; Meng, Y.; Feng, H.; Yang, H.; Xu, B. Estimating Leaf Nitrogen Content in Corn Based on Information Fusion of Multiple-Sensor Imagery from UAV. Remote Sens. 2021, 13, 340. [CrossRef]

22. Wold, S.; Sjöström, M.; Eriksson, L. PLS-regression: A basic tool of chemometrics. Chemom. Intellig. Lab. Syst. 2001, 58, 109-130. [CrossRef]

23. Wold, S.; Ruhe, A.; Wold, H.; Dunn, I.; Dunn, W.J. The collinearity problem in linear regression. The partial least squares (PLS) approach to generalized inverses. SIAM J. Sci. Stat. Comput. 1984, 5, 735-743. [CrossRef]

24. Höskuldsson, A. PLS regression methods. J. Chemom. 1988, 2, 211-228. [CrossRef] 
25. Tahmasbian, I.; Xu, Z.; Abdullah, K.; Zhou, J.; Esmaeilani, R.; Nguyen, T.T.N.; Hosseini Bai, S. The potential of hyperspectral images and partial least square regression for predicting total carbon, total nitrogen and their isotope composition in forest litterfall samples. J. Soils Sed. 2017, 17, 2091-2103. [CrossRef]

26. Barbin, D.F.; ElMasry, G.; Sun, D.-W.; Allen, P. Predicting quality and sensory attributes of pork using near-infrared hyperspectral imaging. Anal. Chim. Acta 2012, 719, 30-42. [CrossRef] [PubMed]

27. Kämper, W.; Trueman, S.J.; Tahmasbian, I.; Bai, S.H. Rapid Determination of Nutrient Concentrations in Hass Avocado Fruit by Vis/NIR Hyperspectral Imaging of Flesh or Skin. Remote Sens. 2020, 12, 3409. [CrossRef]

28. Malmir, M.; Tahmasbian, I.; Xu, Z.; Farrar, M.B.; Bai, S.H. Prediction of macronutrients in plant leaves using chemometric analysis and wavelength selection. J. Soils Sed. 2020, 20, 249-259. [CrossRef]

29. Kohavi, R. A study of cross-validation and bootstrap for accuracy estimation and model selection. In Proceedings of the International Joint Conference on Artificial Intelligence (Ijcai), Montreal, QC, Canada, 20-25 August 1995; pp. 1137-1145.

30. Malmir, M.; Tahmasbian, I.; Xu, Z.; Farrar, M.B.; Bai, S.H. Prediction of soil macro- and micro-elements in sieved and ground air-dried soils using laboratory-based hyperspectral imaging technique. Geoderma 2019, 340, 70-80. [CrossRef]

31. Shen, L.; Gao, M.; Yan, J.; Li, Z.-L.; Leng, P.; Yang, Q.; Duan, S.-B. Hyperspectral Estimation of Soil Organic Matter Content using Different Spectral Preprocessing Techniques and PLSR Method. Remote Sens. 2020, 12, 1206. [CrossRef]

32. Bellon-Maurel, V.; Fernandez-Ahumada, E.; Palagos, B.; Roger, J.-M.; McBratney, A. Critical review of chemometric indicators commonly used for assessing the quality of the prediction of soil attributes by NIR spectroscopy. Trends Anal. Chem. 2010, 29, 1073-1081. [CrossRef]

33. Sillero, A.M.; Pierna, J.A.F.; Sinnaeve, G.; Dardenne, P.; Baeten, V. Quantification of protein in wheat using near infrared hyperspectral imaging: Performance comparison with conventional near infrared spectroscopy. J. Near Infrared Spectrosc. 2018. [CrossRef]

34. Fu, Y.; Yang, G.; Pu, R.; Li, Z.; Li, H.; Xu, X.; Song, X.; Yang, X.; Zhao, C. An overview of crop nitrogen status assessment using hyperspectral remote sensing: Current status and perspectives. Eur. J. Agron. 2021, 124, 126241. [CrossRef]

35. Chew, L.; Prasad, K.N.; Amin, I.; Azrina, A.; Lau, C. Nutritional composition and antioxidant properties of Canarium odontophyllum Miq.(dabai) fruits. J. Food Compos. Anal. 2011, 24, 670-677. [CrossRef]

36. Bai, S.H.; Darby, I.; Nevenimo, T.; Hannet, G.; Hannet, D.; Poienou, M.; Grant, E.; Brooks, P.; Walton, D.; Randall, B.J.P.o. Effects of roasting on kernel peroxide value, free fatty acid, fatty acid composition and crude protein content. PLoS ONE 2017, 12, e0184279.

37. Burger, J.; Geladi, P. Hyperspectral NIR imaging for calibration and prediction: A comparison between image and spectrometer data for studying organic and biological samples. Analyst 2006, 131, 1152-1160. [CrossRef]

38. Nawar, S.; Mouazen, A.M. Optimal sample selection for measurement of soil organic carbon using on-line vis-NIR spectroscopy. Comput. Electron. Agric. 2018, 151, 469-477. [CrossRef]

39. Viscarra Rossel, R.A.; Walvoort, D.J.J.; McBratney, A.B.; Janik, L.J.; Skjemstad, J.O. Visible, near infrared, mid infrared or combined diffuse reflectance spectroscopy for simultaneous assessment of various soil properties. Geoderma 2006, 131, 59-75. [CrossRef]

40. Cozzolino, D.; Morón, A. Potential of near-infrared reflectance spectroscopy and chemometrics to predict soil organic carbon fractions. Soil Tillage Res. 2006, 85, 78-85. [CrossRef]

41. Tahmasbian, I.; Xu, Z.; Boyd, S.; Zhou, J.; Esmaeilani, R.; Che, R.; Bai, S.H. Laboratory-based hyperspectral image analysis for predicting soil carbon, nitrogen and their isotopic compositions. Geoderma 2018, 330, 254-263. [CrossRef]

42. Curran, P.J. Remote sensing of foliar chemistry. Remote Sens. Environ. 1989, 30, 271-278. [CrossRef]

43. Datt, B. Remote Sensing of Chlorophyll a, Chlorophyll b, Chlorophyll a+b, and Total Carotenoid Content in Eucalyptus Leaves. Remote Sens. Environ. 1998, 66, 111-121. [CrossRef]

44. Sun, D.-W. Infrared Spectroscopy for Food Quality Analysis and Control; Academic Press: Burlington, MA, USA, 2009.

45. Salgó, A.; Gergely, S. Analysis of wheat grain development using NIR spectroscopy. J. Cereal Sci. 2012, 56, 31-38. [CrossRef]

46. Zhou, P.; Zhang, Y.; Yang, W.; Li, M.; Liu, Z.; Liu, X. Development and performance test of an in-situ soil total nitrogen-soil moisture detector based on near-infrared spectroscopy. Comput. Electron. Agric. 2019, 160, 51-58. [CrossRef]

47. Moss, A.; Chrystal, P.; Crowley, T.; Pesti, G. Raw material nutrient variability has substantial impact on the potential profitability of chicken meat production. J. Appl. Poult. Res. 2021, 30, 100129. [CrossRef]

48. Nahm, K. Feed formulations to reduce $\mathrm{N}$ excretion and ammonia emission from poultry manure. Bioresour. Technol. 2007, 98, 2282-2300. [CrossRef] [PubMed]

49. Ritz, C.; Fairchild, B.; Lacy, M. Implications of ammonia production and emissions from commercial poultry facilities: A review. J. Appl. Poult. Res. 2004, 13, 684-692. [CrossRef]

50. Moss, A.; Parkinson, G.; Crowley, T.; Pesti, G. Alternatives to formulate laying hen diets beyond the traditional least-cost model. J. Appl. Poult. Res. 2021, 30, 100137. [CrossRef] 